\title{
ESTRATÉGIAS PARA A BUSCA DA GESTÃO DE EXCELÊNCIA: UM ESTUDO DE CASO NO MUNICÍPIO DE CANARANA - MT.
}

\author{
STRATEGIES FOR THE EXCELLENCE MANAGEMENT: A STUDY CASE IN THE \\ CAOUTY OH THE CANARANA-MT
}

\begin{abstract}
RESUMO
O Planejamento Estratégico, difundido a partir dos anos 80, vem sendo adotado por diversas organizações com visão de futuro na iniciativa privada e pública, mas observa-se dificuldade na implementação nos municípios de pequeno porte. Sabe-se que o uso desta ferramenta de gestão necessita de conhecimento, mão de obra qualificada e tecnologia apropriada, pois a ausência destes requisitos pode dificultar sua utilização e ou comprometer seus resultados. Diante disso, questiona-se: por que o município de Canarana ainda não possui o planejamento estratégico como referência em seu processo de gestão? Sendo assim, este trabalho tem a finalidade de realizar um diagnóstico para entender quais são os fatores que dificultam a implementação do Planejamento Estratégico e propor objetivos estratégicos de longo prazo para o município de Canarana. Conclui-se que o município tem uma localização estratégica privilegiada, miscigenação de culturas, diversidade agrícola e pecuária extensiva desenvolvida. Neste sentido, a identificação dos objetivos estratégico, realizada pelos autores e a consolidação Planejamento Estratégico são passos importantes para alavancar o seu desenvolvimento, especialmente na preservação da diversidade ambiental. Por fim, foram ratificadas as hipóteses de falta de cultura de planejamento, recursos humanos com pouca qualificação, mas a hipótese de resistência à elaboração de planejamento foi refutada.
\end{abstract}

Edelvais Oster Ritter ${ }^{1}$

Dirceu Grasel $^{2}$

Palavras: Planejamento, objetivos estratégicos, desenvolvimento socioambiental.

\begin{abstract}
Strategic Planning has been propagated since the 80 s and has been adopted by several forward-thinking organizations in private and public initiatives, but its implementation in small municipalities has been rather difficult. It is known that the use of this management practice requires knowledge, skilled labor and appropriate technology, since the absence of these requirements may hinder its use or compromise its results. Therefore, the question is: why the strategic planning it is not a reference in the management process of the municipality of Canarana? Consequently, this work has the purpose of making a diagnosis to understand what factors hinder the implementation of Strategic Planning, and propose long-term strategic objectives for Canarana. The study concluded that the municipality has

\footnotetext{
${ }^{1}$ Graduada em Economia pela Universidade Federal de Mato Grosso (UFMT). Mestre em Agronegócio e Desenvolvimento Regional pela Universidade Federal de Mato Grosso (UFMT). E-mail: eoritter@yahoo.com.br

${ }^{2}$ Professor da Universidade Federal de Mato Grosso (UFMT).E-mail:dgrasel@ufmt.br
} 
privileged strategic location, miscegenation of cultures, agricultural diversity and developed extensive livestock farming. In this sense, the identification of strategic objectives proposed by the authors and the consolidation of Strategic Planning are important steps to boost its development, especially in the preservation of environmental diversity. Ultimately, the hypotheses that the municipality lacks a planning culture and that its human resources are under-qualified have been ratified. However, the hypothesis that there would be resistance to the formulation of a planning process was refuted.

Keywords: Planning, strategic objectives, social and environmental development.

JEL: H11

\section{Introdução}

Os mato-grossenses e suas instituições agindo de forma espontânea conduziram o Estado a um patamar de destaque, visto que recebeu o rótulo de "celeiro do mundo". Aliado a este cenário percebe-se um esforço para melhorar a gestão dos recursos públicos por meio de métodos. Como estágio inicial em 2012, oito municípios do Estado receberam incentivos para realizar o planejamento estratégico. Em 2013, mais 12 municípios iniciaram o processo. No biênio 2014/2015 outros 20 municípios foram incentivados, sendo os dez que apresentam menor IGF- M - Índice de Gestão Fiscal e os outros dez priorizados pela arrecadação. Portanto, ainda existe um vácuo para atuar com gestão estratégica nos municípios mato-grossenses para fomentar o crescimento e o desenvolvimento de forma ordenada, por meio da metodologia de planejamento e consequentemente crescer em direção a excelência em gestão.

Dentre os municípios que não tem planejamento estratégico está Canarana que se encontra na região leste, classificada como de expansão agrícola e da pecuária no cerrado de acordo com (IBGE, 2011). O Município completou 41 anos, desde a chegada das primeiras famílias. Diante disso, o questionamento a ser respondido é por que o município de Canarana ainda não possui o planejamento estratégico como referência em seu processo de gestão?

As hipóteses iniciais que podem explicar o fato são: 1) falta de cultura de planejamento; 2) resistência dos gestores ao planejamento e; 3) recursos humanos sem qualificação necessária. Sendo assim, este trabalho tem a finalidade de realizar um

diagnóstico para entender quais são os fatores que dificultam a implementação do Planejamento Estratégico e propor objetivos estratégicos de longo prazo para o município 
de Canarana. Os objetivos específicos: 1) realizar um diagnóstico do município de Canarana; 2) desenvolver uma pesquisa qualitativa sobre forças, fraquezas, ameaças e oportunidades para executar análise SWOT do município; 3) elaborar a matriz GUT gravidade, urgência e tendência e; proposição da identidade institucional.

A proposição de objetivos estratégicos tanto pode ser geral como individualizada por município ou por região, para viabilizar a identificação das forças, fraquezas, ameaças e oportunidades, e ainda, para aproveitar as potencialidades locais. O município de Canarana foi escolhido por estar localizado na região leste, ser jovem, e por ter sido colonizado recebendo uma forma diferenciada de criação.

Na primeira seção abordaram-se as teorias que dão sustentação a pesquisa, como planejamento estratégico e planejamento estratégico público. A seção II trata do método passando por todas as fases de elaboração de um planejamento estratégico. A seção III aborda a caracterização do município. Na seção IV foi realizada a análise e discussão dos resultados. $\mathrm{Na}$ seção $\mathrm{V}$ foram sugeridos os objetivos estratégicos prioritários para o município iniciar uma gestão baseada em planejamento de longo prazo. Por fim, apresentam-se conclusões, sugestões, limitações da pesquisa e recomendações para futuros trabalhos.

\section{PLANEJAMENTO ESTRATÉGICO}

Na figura 1 é possível observar cronologicamente a evolução da teoria de planejamento bem como a amplitude tomada ao longo dos séculos.

\section{Figura 1 - Escala de desenvolvimento das teorias de planejamento}

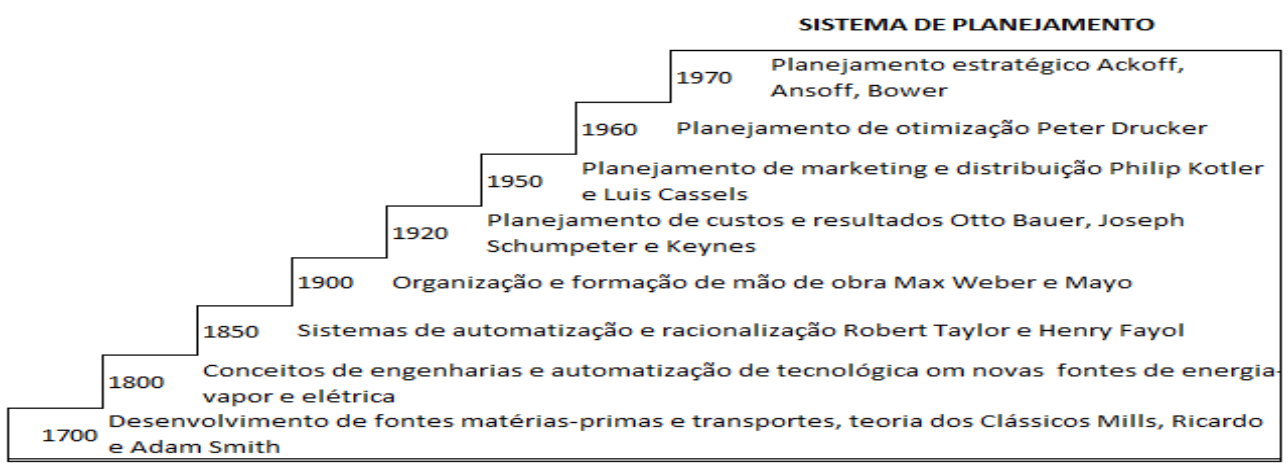

Fonte: RASMUSSEN (1990) 
Segundo Mintzberg et. all. (2000), a Escola de Planejamento tem sua origem nos trabalhos de Ansoff (1965); Steiner (1969), que separou o processo em etapas, premissas, desenvolvimento e implementação. Lorange (1979), Ackoff (1979) e Porter (1986) entre outros, que prestaram contribuições importantes sobre o planejamento estratégico, aliado à alta e estratégica administração como ciência reconhecidamente amadurecida. O planejamento estratégico foi escolhido pela característica de formalidade que é condição precípua da atuação dos órgãos das esferas Federal, Estadual e Municipal e análise SWOT Forças (Strenghts), Fraquezas (Weaknesses), Oportunidades (Opportunities) e Ameaças (Threats). Como este estudo está baseado num município, portanto é um estudo de caso que, por vez, deve seguir dentre outras leis a Constituição Federal e Estadual, Lei das finanças públicas, Lei de compras e contratações, Lei de Responsabilidade Fiscal (LRF) etc.

A Administração Científica com seus pensadores sistematizou e conceituou o planejamento como um processo. Taylor (1911) afirma que há necessidade da substituição da improvisação pela ciência, por meio do planejamento e do método, e assim estabelece um dos grandes princípios da administração: o Princípio de Planejamento.

Para Fayol (1950), Administrar é: prever - visualizar o futuro e traçar plano de ação; organizar - formar a base do duplo organismo material e social; comandar - dirigir e orientar o pessoal; coordenar - interligar, harmonizar os atos e os esforços coletivos; e controlar - comparar - verificar se o planejado e o executado foram cumpridos de acordo com as regras estabelecidas.

Na Teoria Neoclássica, Drucker (1962, p.131) traz que as funções clássicas do gestor são:

planejamento, organização, direção e controle - são funções administrativas que formam o processo administrativo, onde esse processo é cíclico, dinâmico e interativo, e o planejamento, como função administrativa, determina antecipadamente quais os objetivos e o que deve ser feito para alcançá-los. E ainda, que o planejamento não diz respeito a decisões futuras, mas às implicações futuras de decisões presentes. 
Segundo Ackoff (1974, p.4), “O planejamento é um processo contínuo que envolve um conjunto complexo de decisões inter-relacionadas que podem ser separadas de formas diferentes". Ele apresenta as cinco partes: 1) planejamento dos fins: esmiúça os detalhes desejados de futuro; 2) planejamento dos meios: define os caminhos a serem seguidos para atingir os fins; 3) planejamento organizacional: sistematiza os requisitos para realizar os meios propostos; 4) planejamento de recursos: dimensiona os recursos humanos, materiais e financeiros; 5) planejamento de implementação e controle: atividade de planejar, gerenciar e implantar.

Oliveira (2002) considera os grandes níveis hierárquicos que podem se distinguir em três tipos de planejamento: Estratégico; tático; e operacional.

De forma genérica, pode-se relacionar os tipos de planejamento aos níveis de decisão.

Figura 2 - Tipos e sentido de planejamento e a correlação com os níveis de decisão
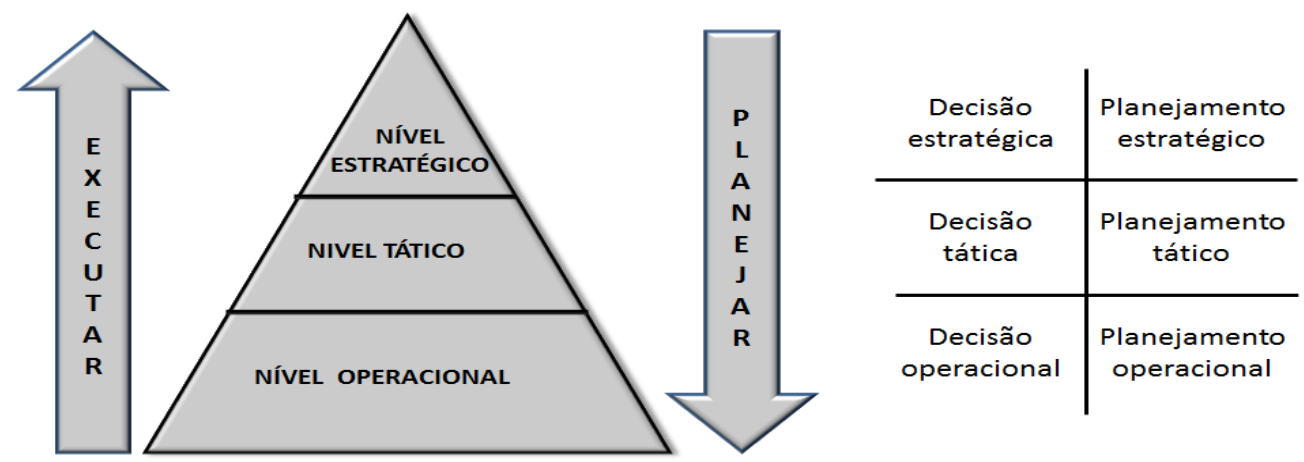

Fonte: Adaptada de OLIVEIRA (2002)

O planejamento estratégico relaciona-se com os objetivos de longo prazo, com ações estratégicas para alcançá-los e que afetam a organização, enquanto que o planejamento tático relaciona-se com os objetivos de curto prazo e com ações táticas que afetam somente parte da organização.

Segundo Kotler (2000, p.87), o planejamento estratégico é: um processo gerencial de desenvolver e manter um ajuste viável entre objetivos, habilidades e recursos de uma organização e as oportunidades de um mercado em contínua mudança. $\mathrm{O}$ objetivo do planejamento estratégico é dar forma aos negócios e produtos de 
uma organização, de modo que eles possibilitem os lucros e o crescimento almejado.

Kotler (2000) ainda ressalta que a principal meta do planejamento estratégico é auxiliar a organização priorizar e organizar seus negócios de modo a manter-se saudável. Para ele o planejamento exige ações em três áreas-chave: primeira, gerenciar os negócios. A segunda envolve a avaliar os pontos fortes. E a terceira é a estratégia. Kaplan e Norton (1997) definem estratégia como opção de segmento de mercado e cliente que a organização pretende atender, identificando os processos internos críticos nos quais deve atingir a excelência para concretizar sua proposta.

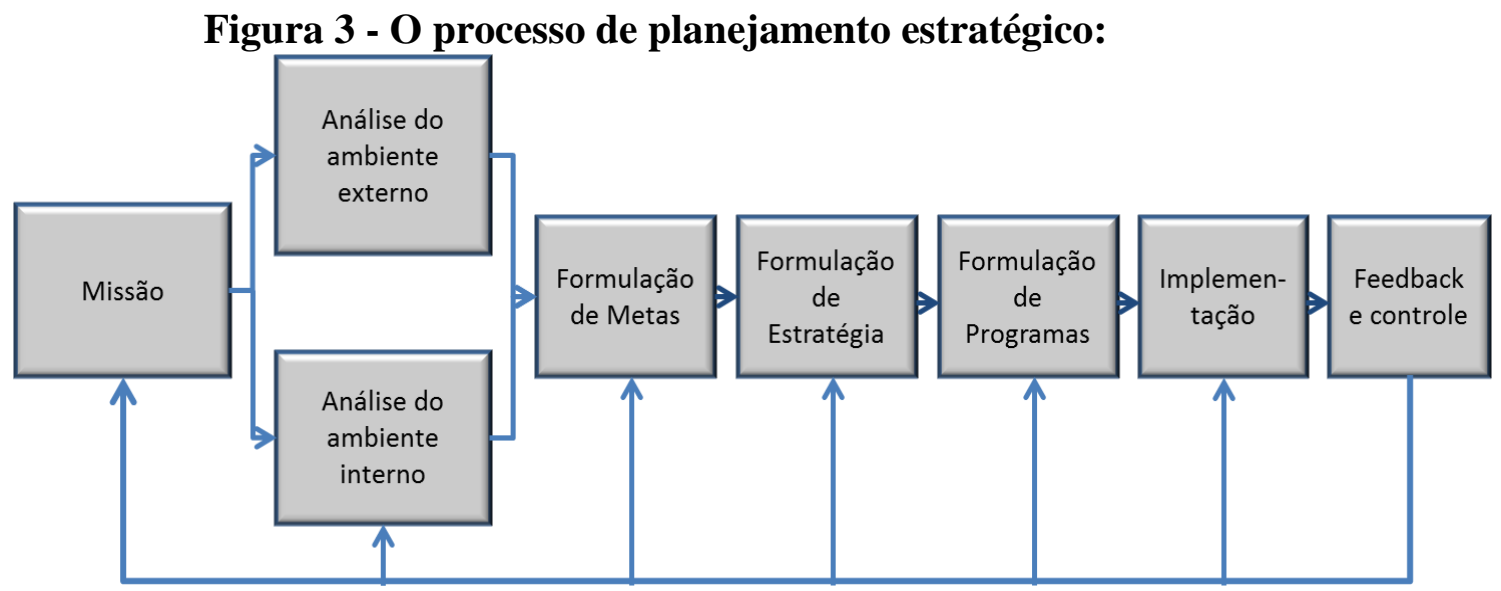

Fonte: KOTLER (2000, p, 98)

\subsection{Planejamento Estratégico Municipal}

Segundo Pfeiffer (2000), os municípios brasileiros encontram-se num processo de profunda mudança, que ganhou força com a $\mathrm{CF} / 88$, quando foi transferida aos municípios uma série de competências para delinear o seu desenvolvimento e definir o seu destino, apesar da amplitude dessas competências. Entretanto, a descentralização e democracia são princípios políticos e administrativos mais modernos. Aureliano (1996) ressalta que nessas circunstâncias, a descentralização foi um processo puramente reativo, não um projeto estruturado para implantação paulatina. E o resultado foi que a transferência de responsabilidades não foi acompanhada por uma preparação e um fortalecimento dos municípios, para que estes tivessem condições reais de assumir os seus novos compromissos. 
Pfeiffer (2000) traz ainda que os dois principais instrumentos de planejamento urbano no Brasil são a Lei Orgânica e o Plano Diretor. Sendo o Plano Diretor obrigatório aos municípios com mais de 20.000 habitantes e a Constituição oferece apenas uma orientação geral, dizendo que o seu objetivo é "ordenar o pleno desenvolvimento das funções sociais da cidade e garantir o bem-estar de seus habitantes" (CF/88 art. 182).

A Constituição ainda orienta que a elaboração desse Plano deve ser participativa e deve-se considerar os interesses das organizações civis locais. Entretanto, os detalhes desses procedimentos são definidos na Lei Orgânica e podem variar de município para município, respeitando a legislação federal ou estadual. Aureliano (1996) frisa que para ser eficiente na sua implementação, à descentralização exige o desenvolvimento de uma capacidade gerencial, o que ocorre paulatinamente.

Pfeiffer (2000) ressalta que, ao contrário de um Plano Diretor, o Plano Estratégico não é uma norma legal e sim um contrato político e social, cuja execução corresponde àquelas partes que têm a competência, a capacidade e a maturidade para fazê-lo. No entanto, o plano funciona como meio de pressão pública para promover o cumprimento dos seus objetivos e traçar um vetor de longo prazo, reduzindo dessa forma a discricionariedade do gestor no sentido de seguir o caminho que bem lhe convier.

\subsection{Planejamento Estratégico Focado na Administração Pública}

Matus (1996) argumenta a inseparabilidade de aspectos políticos e econômicos, que a época era inconcebível aos planejadores com crença específica no econômico dos processos de planejamento e desenvolvimento. O argumento de Matus tornou-se sólido após a sua atuação como funcionário público no Chile, no governo do presidente Salvador Allende, confirmando a ruptura do planejamento normativo. A crítica ao planejamento tradicional acentuou-se em rincões de conhecimento aparentemente desconexos da teoria econômica tradicional onde se fundamentava o planejamento do desenvolvimento.

Somaram-se novos fatos como a Teorias do Caos, Teoria Geral dos Sistemas, Cibernética, Teoria da Informação entre outras. Esse conjunto de fatores provocou novas reflexões e Matus (1980) escreveu Planejamento Situacional, obra que torna imperativa uma teoria da ação social como base para o método de planejamento situacional. 
Para Matus (1993) o ato de gerir um ente federado requer um conjunto de atributos que estão além de uma teoria, sendo necessário também, conhecimento dos sistemas sociais para consolidar o poder de barganha e superar as dificuldades postas. O gestor deve ter governabilidade para seguir o caminho traçado e comprovar a competência de gerir. Segundo ele o ato de gerir requer o inter-relacionamento de três variáveis do que denominou triângulo de governo.

B (Governabilidade)

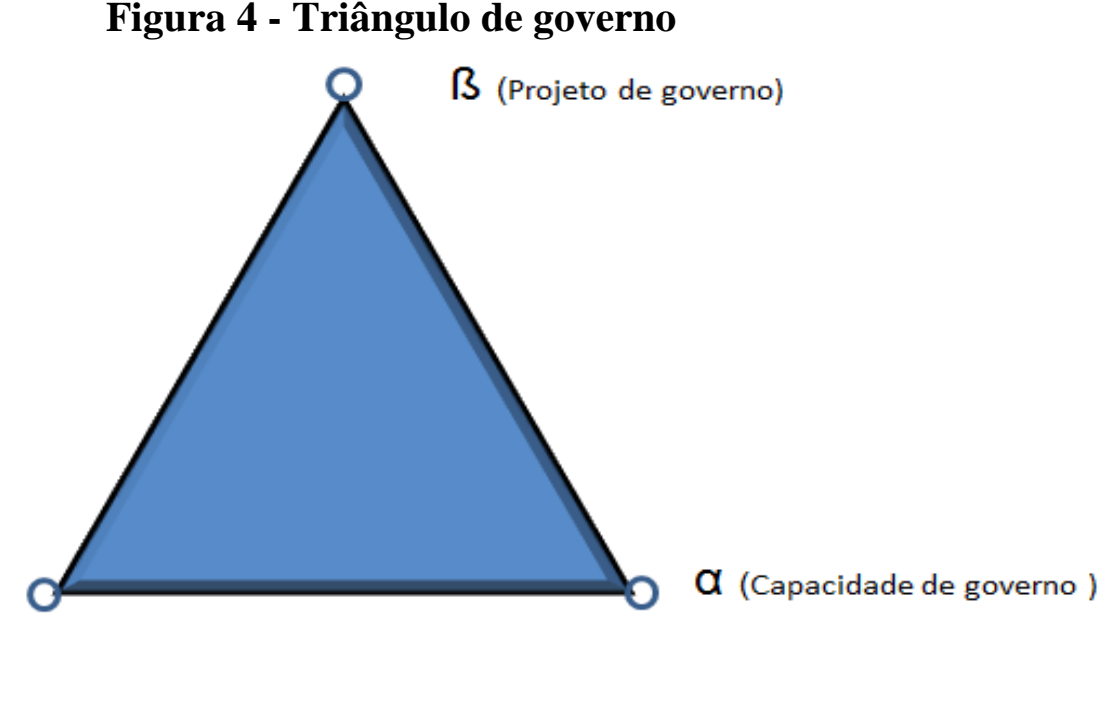

Fonte: Matus (2006)

O projeto de governo consiste na priorização de problemas que o gestor se propõe a encarar utilizando-se de estratégia articulada e adequada, para auferir resultados no período da gestão, vez que impacta na possibilidade de resolvê-los e na factibilidade política desse desafio (TONINI 2005).

A capacidade de governo está intrinsecamente ligada ao preparo da equipe de gestão, experiência, compreensão teórico prática e a clareza dos problemas a serem enfrentados diante dos objetivos sociais estabelecidos no projeto de governo e de realizar o inter-relacionamento e o refinamento das ações. 
Governabilidade está diretamente ligada aos pesos das variáveis que o ator monitora, das ações que não monitora adicionada à percepção do gestor. Esta percepção possibilita discernir dentre os atores envolvidos os que demonstram habilidade para estabelecer alianças, enfrentamentos decisivos, controle da situação viabilizando uma análise dos problemas priorizados, bem como as estratégias para tornar os objetivos factíveis (MATUS, 1993).

Na revisita efetuada às diversas teorias de planejamento foi possível observar que, quando se trata de Brasil, ainda existe um processo incipiente de pensar a longo prazo em qualquer das esferas observadas. Apesar de existir no país ilhas de excelência há uma infinidade de municípios carentes de metodologia para atuar assertivamente. Para isso é indicado agir preventivamente para auxiliar os gestores a pensar em como aplicar os recursos públicos ao invés de realizar as análises após o ocorrido sem oportunidade de mudar o rumo do que já está consumado em termos de aplicação do orçamento. Diante disso, faz-se necessário o estabelecimento de políticas públicas nas diversas esferas, ou seja, Federal, Estadual e Municipal bem como o desenvolvimento paulatino da cultura de pensar a longo prazo, por meio de políticas públicas estabelecidas.

\section{PROCEDIMENTOS METODOLÓGICOS}

A pesquisa inicia-se com a exposição ao Secretário de Administração de um projeto para propor objetivos estratégicos para o município de Canarana. Ele mencionou a realização de um trabalho envolvendo os diversos setores da sociedade e sugeriu a participação como pesquisadora, uma vez que os conteúdos a serem estudados tinham similaridade e os atores envolvidos eram os mesmos.

Então, participando da realização dos fóruns, ouvindo os depoimentos, integrando os grupos de discussões, preenchendo formulários com o resultado dos brainstormings realizados, ora em um grupo ora em outro, participando das apresentações e levantando os dados para realização do diagnóstico iniciou-se a pesquisa. Desses fóruns participaram secretários do município, vereadores, empresários dos diversos segmentos. Esses fóruns 
foram contratados pela ADECAN - Associação de Desenvolvimento de Canarana e realizados pelo SEBRAE.

Para facilitar o levantamento de dados após o alinhamento conceitual, foi dividido nos seguintes segmentos: Setor de Produção Agropecuária e Agricultura Familiar; Setor de Produção Agropecuária Organizacional; Setor de Infraestrutura; Setor de Produção em Geral; Setor de Comércio; Setor da Cultura e Identidade; Setor de Educação; Setor de Saúde; Setor de Serviços; Setor de Turismo. A primeira dinâmica proposta foi à realização de um Diagrama de Venn com a finalidade de localizar as instituições em relação à proximidade da gestão e interação estadual com o município. Em seguida os representantes de segmento realizaram reuniões com a comunidade no sentido de ampliar a discussão e levantar novos dados sobre potencialidades e estrangulamentos, que foram sintetizados pelos representantes e apresentados aos demais participantes do fórum.

Após a identificação dos fatores de estrangulamento, potencialidades serão organizadas por ambiente externo - ameaças e oportunidades e ambiente interno - forças e fraquezas. De posse dessa planilha serão priorizados os fatores e serão atribuídas as notas de acordo com parâmetros de gravidade, urgência e tendência conforme estabelecido na Matriz GUT. A técnica desenvolvida por Kepner e Tregoe (1981), procura clarificar as ações prioritárias e as letras GUT estão correlacionadas aos quesitos que devem ser respondidos onde $\mathrm{G}$ igual a gravidade, $\mathrm{U}$ igual a urgência e $\mathrm{T}$ igual a tendência.

Com esses cuidados, espera-se identificar os fatores que mereçam Objetivo Estratégico e que possam atuar por integração e refinamento, ou seja, que proporcione reação em cadeia. O grande desafio do planejador é identificar o que de fato é estratégico, devido à grande quantidade de ações que um município demanda.

O meio principal definido para realizar a análise qualitativa foi SWOT e aplicação da matriz GUT. O levantamento inicial de forças, fraquezas, ameaças e oportunidades resultaram em 203 (duzentos e três) itens, sendo: 52 (cinquenta e duas) forças e 52 (cinquenta e duas) fraquezas, 18 (dezoito) ameaças, 81 (oitenta e uma) oportunidades. Diante desse total tornou-se inviável aplicar diretamente GUT para priorização. Após a organização da análise SWOT, foi necessário correlacionar as forças, fraquezas, ameaças, e 
oportunidades com os setores pesquisados utilizando uma matriz binária, a priorização aplicada não trouxe resultado ideal.

Como foi percebida a interligação principalmente entre os setores saúde com 35 (trinta e cinco) ocorrências e educação com 77 (setenta e sete) ocorrências, realizou-se o somatório entre saúde e educação que resultou em 112 (cento e doze) ocorrências, a partir daí transformou-se em percentual, a saúde com 31,25\% e a educação com 68,75\%. Dessa forma, foi atribuído o peso de 1,5 para saúde e 2 para educação. A aplicação da teoria de Pareto era necessária, pois ainda eram muitos dados. Como saúde e educação cruzavam também com infraestrutura, utilizou-se o somatório com os pesos atribuídos à saúde e educação quando as ocorrências impactavam simultaneamente e atribui-se o peso 3 nessas circunstâncias. Realizado o procedimento, aplicou-se Pareto para separar os 20\% significativos. Como as sugestões ainda eram muitas, os objetivos do milênio foram associados à matriz.

Por se tratar de um município que recebe transferência estadual e federal optou-se por cruzar esses dados com os objetivos do milênio estabelecidos pelas Nações Unidas, em Nova Iorque e setembro de 2000, que reflete a preocupação de 191 países que participaram do Fórum do Milênio. Dessa vez, observou-se cada sugestão e avaliou se havia ou não impacto para atingir os objetivos estabelecidos, a partir desse momento; no sentido de amiudar os dados aplicou-se mais uma vez Pareto. O restante passou pelo crivo da avaliação GUT.

\section{CARACTERIZAÇÃO DO MUNICÍPIO}

Canarana é um município pequeno da região leste mato-grossense e, segundo o IBG (2010), em 2010, o município contava com uma população 18.754 habitantes, com taxa de urbanização 78,9\% (rural com 21,1\%). Deste total, 51,5\% são homens e 48,5\% e mulheres. $10,3 \%$ dos habitantes acima de quinze anos não sabem ler e escrever, representando 1.403; pessoas deve-se levar em consideração que 1.349 habitantes são de etnias indígenas e, dessas, 271 pessoas vivem em área urbana e 1.078 na área rural, o que contribui para o aumento do percentual de habitantes que não sabem ler. 
Ainda, conforme (IBGE/2010), do total de 5.655 domicílios particulares, 3,9\% possuem tipos de saneamento total adequado, $81,3 \%$ semiadequado e $14,9 \%$ saneamento inadequado. Ressalta-se ainda, que, desse total, 4.624 domicílios são urbanos. Da população total 17.610 pessoas são residentes em domicílios particulares permanentes, sendo que 14.037 pessoas são da área urbana e 3.573 da área rural.

\subsection{Classificação da Região/ Localização}

De acordo com IBGE (2011), a região está classificada como de expansão da agricultura e da pecuária no cerrado, O Município de Canarana, que é objeto do estudo, está localizado no Vale do Xingu e, seu território, o principal acesso ao Parque Nacional do Xingu. Está centralizado entre os municípios de Gaúcha do Norte, Querência, Água boa e Ribeirão Cascalheira, com uma área de 1.087.000 ha, com uma temperatura média de $25^{\circ}$ C. A vegetação é composta de cerrado (55\%), mata (40\%), varjão (5\%). Banhado pelas Bacias Xingu, Araguaia e pelos Rios Kuluene, Sete de Setembro, Suiá Missu, Xingu, Tanguro, Vanicke com altitude de $390 \mathrm{~m}$.

Figura 5 - Mapa de localização das BRs 158, 163 e 364

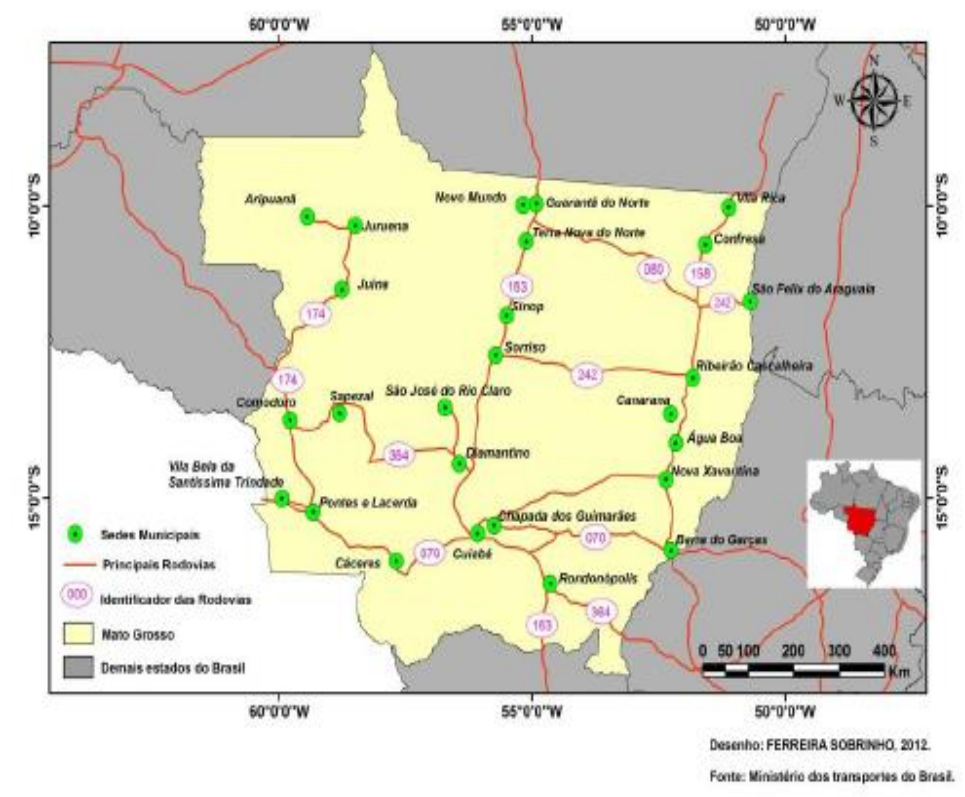

Fonte: Ministério os Transportes o Brasil (2012).

Fonte: Ministério dos Transportes Apud RIBEIRO (2013) 
Com este mapa é possível observar a localização de Canarana em relação aos municípios situados no norte do Estado/MT e que se encontram em um nível de desenvolvimento diferenciado, entre os localizados no paralelos $12^{\circ} \mathrm{S}$ e $13^{\circ} \mathrm{S}$ entre os meridianos $56^{\circ} \mathrm{W} / 57^{\circ} \mathrm{W}$. Além disso, o escoamento agrícola e pecuário pode ser transportado em direção aos portos do nordeste com ganhos significativos, assim que concluídas as obras da BR-158.

\subsection{Distribuição de Culturas Agrícolas.}

O Município traz intrínseca a cultura dos minifúndios que usavam da diversidade de pequenas produções para sobreviver e com o aprendizado do uso das terras matogrossenses sedimentou uma postura dinâmica em relação à produção. A região se destaca pelo cultivo da segunda safra. Na safra de 2012/2013, 47.730 há de milho foram plantadas. Outros 15.000 ha com sorgo, milheto, crotalária também de segunda safra que complementam a movimentação financeira de até 50 milhões ano. A atividade pecuária ocupa uma área de 455.127ha de pastagens, com um rebanho de 384.426 cabeças. Os produtores implantaram a integração de lavoura pecuária fazendo a suplementação dos rebanhos no período da seca. Esse conjunto de fatores demonstra o amadurecimento dos produtores, o que reflete no IDH-M que analisa um conjunto de dados.

\section{3 Índice de Desenvolvimento Humano}

O Índice de Desenvolvimento Humano Municipal (IDH-M) do município passou de 0,710 para 0,761 no IDH-M em 2000, expressando um crescimento de 7,18\%. O requisito mais representativo para o crescimento foi a Longevidade, com 47,1\%, seguido pela Renda com 32\%, e pela Educação, com 20,9\%. Em 2000, segundo a classificação do PNUD, o município encontrava-se numa situação boa em relação aos demais municípios brasileiros, uma vez que ocupa a $1.544^{\mathrm{a}}$ e quando comparado aos municípios do Estado, Canarana ocupa a $33^{\mathrm{a}}$ posição (PNUD, 2000).

\subsection{Saneamento Básico}

O saneamento básico é um indicador que merece medida prioritária, tendo em vista que 3,9\% dos domicílios particulares têm saneamento total adequado; 81,3\% semiadequado e $14,9 \%$ saneamento inadequado. A falta de saneamento traz reflexos diretos à saúde 
fazendo com que haja desperdícios de recursos com ações corretivas ao invés de atuar de forma definitiva e preventiva. Livrando, dessa forma, principalmente crianças e idosos de ir a óbito precocemente, bem como preservando a saúde dos demais habitantes.

\subsection{Educação/ Analfabetismo}

O resultado apresentado pelo IDEB observado e metas projetadas para $4^{\mathrm{a}}$ série/ $5^{\mathrm{o}}$ ano e $8^{\mathrm{a}}$ série/ $9^{\circ}$ ano no período 2007 a 2013 demonstrou que o município sistematicamente tem atingido as metas propostas. Nessa situação, conforme indicado pela metodologia de planejamento, é momento de rever a meta como iniciativa do município, pois o IDEB atinge todas as escolas de municípios brasileiros tornando inviável uma medida nacional pela disparidade de resultados.

As escolas do município devem ter um projeto único coordenado pela secretaria municipal de educação, pensado em conjunto e próprio à localidade; independente de serem públicas estaduais, municipais ou mesmo privadas, este projeto atuará como fator de retenção do aluno na escola, e pode desenvolver uma cultura de busca e inovação motivando o principal ator que é o aluno para se engajar e propor novos projetos.

Essas ações são necessárias para aplacar principalmente o analfabetismo em adultos com percentual de 10,3\% habitantes maiores de quinze anos que não sabem ler e escrever e, ainda, tem como peculiaridade o contingente de 1.349 habitantes de etnias indígenas, dessas, 271 pessoas vivem em área urbana e 1.078 na área rural. Em função disso, o município deve adotar uma política de educação diferenciada no sentido de integrar esses habitantes, vez que $80 \%$ que residem em aldeias próximas são do município.

\subsection{Saúde}

Com relação à saúde, o TCE-MT, como órgão que fiscaliza o controle externo e a aplicação de recursos públicos, acompanha os dados por meio de indicadores. Para efeito da classificação do conceito existe uma comparação entre o município com a média do Estado e Brasil. Há indicadores que refletem resultados abaixo das médias como a taxa de mortalidade infantil a partir de 2010; a taxa de internação por infecção respiratória aguda de 2008 a 2013; a taxa de detecção de hanseníase de 2008 a 2010 e 2012/2013; a taxa de incidência de dengue em 2008. 
A sugestão é que o município estabeleça parcerias com a União, Estado para erradicar as doenças como a hanseníase, tuberculose, dengue que são passíveis de administração. A mortalidade infantil demonstrou resultado abaixo das médias nos últimos 4 anos consecutivos.

\subsection{Segurança}

Os indicadores para acompanhar a política de segurança separam as regionais com vários municípios e Canarana pertence à regional de Água Boa com a participação de 10 (dez) municípios circunvizinhos. Pelos dados apresentados a região encontra-se classificada com conceito "Boa Regular" para indicadores padronizados e índice de vitimização e criminalidade e "Regular" para índice de variação do modelo de avaliação da política de segurança pública (TCE-MT, 2014).

Dos dados o mais comprometedor é a taxa de homicídios em mulheres com 0,50; seguido pela de crimes contra o patrimônio - veículos com taxa de 0,42; a taxa de violência letal intencional com 0,24. Estas taxas direcionam a gestão para agir pontualmente para assegurar a segurança pública.

A política de segurança aparece classificada com conceito "Boa Regular" para indicadores padronizados e índice de vitimização e criminalidade e "Regular" para índice de variação do modelo de avaliação da política de segurança pública.

\subsection{Produto Interno Bruto}

Em 2011 o Produto Interno Bruto (PIB) a preços correntes foi de R \$ 529,5 milhões reais, assim distribuídos: o valor adicionado bruto da agropecuária foi de R \$ 147,1 milhões; da indústria R\$39,1 milhões; de serviços $\mathrm{R}$ \$ 287,0 milhões e de produtos líquidos de subsídios R\$ 56,1 milhões. Representando 28\%, 7\%, 54\% e 11\% respectivamente, e com um PIB per capita R\$ 27.854,53. A variação do PIB no período de 2006 a 2011 tem um comportamento que oscila: de 2006/2007, o crescimento foi de R\$ 41,5 milhões; de 2008/2009 cresceu em R\$ 116,6 milhões; de 2008/2009 reduziu em R\$ 42,5 milhões. De 2009/2010 houve um crescimento de R \$ 39,4 milhões e 2010/2011 um crescimento de R \$ 162,4 milhões (IBGE, 2011). 
Com relação ao PIB, pode-se dizer que, apesar das ameaças da crise mundial de 2008 e as medidas internas para amenizar seu impacto, não foram suficientes, mesmo tratando-se de município pequeno ligado ao agronegócio, entretanto podem-se verificar as oscilações que ocorreram. Um decréscimo R \$ 2,5 milhões, de 2008/2009, uma vez que a composição do PIB tem com fator o PIB agropecuário com $28 \%$ e o PIB serviços com $54 \%$ que juntos representam $81,98 \%$ do total.

\section{9. Índice de Gestão Fiscal}

Foram estabelecidos parâmetros, quanto à classificação, com os seguintes conceitos: A (Gestão de Excelência, acima de 0,8001 pontos); B (Boa Gestão, entre 0,6001 e 0,8 pontos); C (Gestão em Dificuldade, entre 0.4004 e 0,6 pontos); e D (Gestão Crítica, inferior a 0,4 pontos).

Tabela 1 - IGF-M. de 2009 a 2012.

\begin{tabular}{|c|c|c|c|c|c|c|c|}
\hline \multicolumn{8}{|c|}{$\ldots$} \\
\hline Ano & Municipio & IGF Receita Própria & IGF Gasto Pessoal & IGF liquidez & IGF Investimento & IGF Custo Divida & IGF Geral \\
\hline 2009 & 9 CANARANA & 0,3786 \& & 0,5614 uㅔ & 0,00008 & 1,0000 A & 0,8517 . & 0,5217 \& $46^{\circ}$ \\
\hline 2010 & 0 Canarana & 0,5149 셤 & 0,4091 슴 & 0,0000 & 1,0000 A & 0,9107 A & 0,5240 \& 320 \\
\hline 2011 & 1. CANARANA & 0,4724 A & 0,4535 셤 & 0,5987 & 0,9758 A & 0,9248 A & 0,6551 兯 70 \\
\hline 2012 & 2 CANARANA & 0,5929 셤 & 0,5309 A A & 0,6115 ศ & 1,0000 A & 0,9771 A & 0,7132 舟 50 \\
\hline
\end{tabular}

Fonte: TCE (2014)

Com os dados disponíveis do IFG-M de 2009 a 2012, percebe-se que o município, no quesito receita própria, migrou de gestão crítica em 2009 para gestão em dificuldade de 2010 a 2012. Em gastos com pessoal manteve-se no período de 2009 a 2012 em gestão em dificuldade. Em liquidez com gestão crítica em 2009 e 2010, migrando em 2011 para gestão em dificuldade e 2012 passando para Boa Gestão. Em investimento, assim como custo da dívida de 2009 a 2012, manteve-se em gestão de excelência. No índice geral em 2009 e 2010 foi classificado como gestão em dificuldade e 2011/2012 passou para boa gestão. No ranking de Mato Grosso, Canarana, nesse período foi de $46^{\circ}$ para $5^{\circ}$ lugar. (TCE-MT, 2014). Este acompanhamento torna visível tanto ao gestor como à sociedade o 
desempenho e avaliação para buscar o ajuste total dos índices com indicativo prioritário ao gasto com pessoal e a receitas próprias.

\subsection{Responsabilidade Socioambiental}

Segundo apresentação elaborada pela Secretaria de Agricultura e de Meio Ambiente do Município, com base no banco de dados, nos últimos 5 anos aumentou a área plantada sem fazer novos desmatamentos, mas recuperando áreas de pastagem degradada. Também foi o primeiro do Vale do Araguaia a implantar uma Central de recolhimento de embalagens fazendo a logística reversa, onde as embalagens vazias de agrotóxicos são devolvidas. Há 8 (oito) anos esta central recebe embalagens, quando limpas são prensadas e destinadas à reciclagem e quando contaminadas são enviadas para serem incineradas por empresas especializadas. Em 2013, a previsão foi de receber e transportar 620 toneladas de embalagens que em outros tempos eram queimadas, enterradas, jogadas nos rios ou no cerrado (CANARANA, 2013).

Figura 6 - Pontos de GPS num trabalho de campo

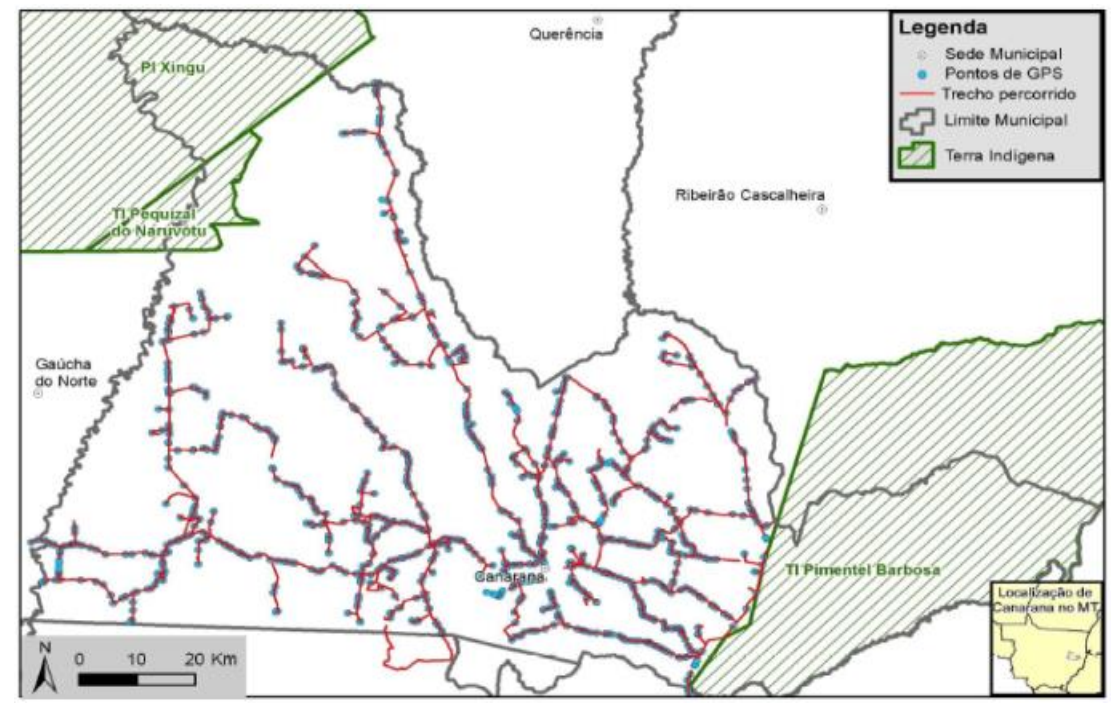

Fonte: Apresentação ISA (2012)

O trabalho de campo realizado pelo ISA (2012), nos meses de abril e maio, com mais de 900 pontos de GPS registrados, com 250 fotos e $1700 \mathrm{~km}$ percorridos, reafirma que a utilização de tecnologia como o georreferenciamento permite a identificação das nascentes e consequentemente o monitoramento efetivo. Esses dados podem tornar-se a base para a elaboração de projetos com visão sistêmica, onde percebe o ambiente com ações integradas. 


\section{Figura 7 - Rede hidrográfica de Canarana}

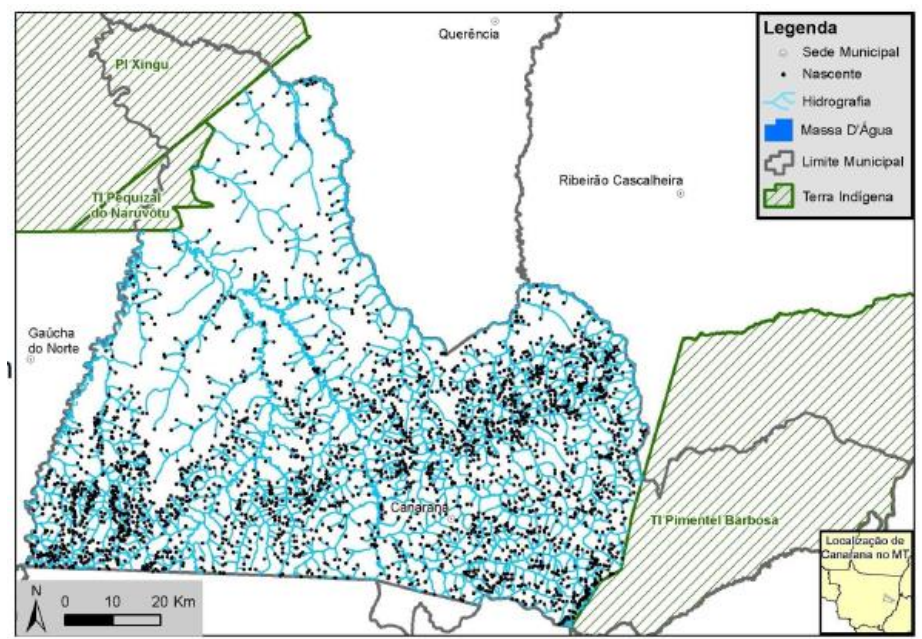

Fonte: Apresentação ISA (2012)

Conforme ISA/2012, o município tem registrado 2.751 nascentes com um curso d'água de $5.900 \mathrm{~km}$. Estes números provocam uma reflexão sobre a importância de preservação socioambiental e que a falta de programas podem levar ao desequilíbrio da região, provocando não apenas a falta de água como também a possibilidade de desertificação pelo conjunto de ações inadequadas e pelas características do solo, da vegetação, clima etc.

Diante dos fatores socioambientais, o município deve escolher como integrar a matriz de sustentabilidade englobando os diversos setores e atores envolvidos. Ocorre no município por meio de responsabilidade compartilhada, desde a campanha Y Ikatu Xingu em Mato Grosso, onde os envolvidos entenderam o Rio Xingu como um bem comum e lutam por sua preservação. Criada em 2004, pelo ISA a campanha é resultado da união e participação de agricultores familiares, produtores rurais, comunidades indígenas, pesquisadores, movimentos sociais e organização da sociedade civil. Y Ikatu Xingu significa "salve a água boa do Xingu" na língua Kamaiurá (VILLAS BOAS, 2012).

Nos fóruns realizados em 2013, surgiram sugestões como: falta de alternância para coletas seletiva de lixo; destinação inadequada de lixo - doenças derivadas; falta de espaço próprio para lixo e seus derivados - aterro sanitário; buscar parcerias com os órgãos estadual e federal que regulam a matéria ambiental, de modo a agilizar os processos de licenciamento ambiental (IBAMA/SEMA); instalação de lixeiras e manutenção de ruas, 
avenidas, praças e órgãos públicos (ginásios, parque de exposição, pronto socorro, delegacia, etc.).

O Município faz parte da Bacia do Rio Xingu composta pelos Estados de MT/PA com 51 milhões de hectares, desse total 17,7 milhões estão no Estado/MT. Segundo Alves (2009, p.2), “Área de Preservação Permanente - APPS são definidas como áreas com cobertura de vegetação nativa, com função ambiental de preservar os recursos hídricos, a paisagem, a estabilidade geológica, proteger o solo e assegurar o bem-estar das populações humanas". No Seminário APP Conama em 2009 foi apresentada a composição do perfil socioambiental das nascentes do Xingu: 3 unidades de conservação estaduais; 12 terras indígenas, sendo 6 integralmente na bacia; 35 municípios, sendo 7 integralmente na bacia; 46 assentamentos rurais, com 27 integralmente na bacia e aproximadamente 270 mil habitantes.

O sistema de semeadura direta apelidado de "muvuca" - nesse sistema, as espécies são combinadas para que ocupem diferentes alturas na mata ao longo do tempo, de forma que uma planta auxilie o crescimento da outra com uso de máquinas, possibilitando o reflorestamento de grandes áreas com menos trabalho, eficiência econômica e ecológica. Após seis anos de campanha apresentou alguns resultados como: menos trabalho, eficiência econômica e ecológica, 2.400ha em processo de restauração florestal, criação da rede de sementes nativas do Xingu e pela demanda trouxe geração de renda para 300 famílias de agricultores familiares e indígenas. Em cinco anos foram comercializadas 75 toneladas de sementes, com uma renda de R 700 mil (VILLAS BOAS, 2012).

O ponto de partida para a sensibilização e mobilização da comunidade escolar foi utilizando o projeto de Governança Florestal e a campanha Y Ikatu Xingu, em maio de 2006 realizou o Festival de Sementes de Canarana, com aproximadamente quatro mil alunos e com a participação de 14 escolas, que devem coletar sementes de espécies nativas para abastecer o viveiro municipal, sensibilizar a comunidade sobre o tema ambiental e incentivar o aprendizado sobre a importância das matas de beira de rio (VILLAS BOAS, 2008). Ressalta-se que o festival de sementes continua ocorrendo anualmente com as escolas. 
A comunidade Yudja realizou pesquisa de campo reunindo jovens e anciãos para a identificação da matriz, do calendário das espécies e dos seus principais dispersores e polinizadores, com a finalidade identificar os tipos de árvores nativas, facilitar a coleta das sementes, bem como registrar os dados as novas gerações (VILLAS BOAS, 2008).

\section{ANÁLISE E DISCUSSÃO DOS RESULTADOS}

\subsection{Análise Quantitativa}

A previsão no planejamento é um ato relevante para aplicação do orçamento, porém, quando ocorre uma variação a menor de aproximadamente $21 \%$, significa que, mesmo utilizando uma metodologia para elaborar a previsão, o valor foi minimizado e se tornou pouco eficaz, inviabilizando a aplicação do recurso de forma programada, bem como restringindo a possibilidade de investimentos. Falar de previsão de orçamento (receita) é uma questão mais que puramente técnica de cumprir a Lei 4320 art. 12, uma vez que traz reflexos políticos.

A Receita Corrente entre 2007/2013 demonstrou um crescimento de 19\%. Em 2008 eclodiu uma crise mundial, no primeiro momento, nos Estados Unidos e Europa; que fez o governo brasileiro, prevendo redução de consumo mundial, criar mecanismos para o aumento do consumo interno. Nesse sentido fez ajustes reduzindo temporariamente impostos para os produtos chamados de "linha branca" para minimizar os efeitos da crise. A redução do imposto sobre produtos industrializados - IPI, que é um dos principais componentes para composição do fundo de recursos às transferências correntes da União para os Estado e Municípios, ocorreu redução nas transferências a todos os entes federados. Quando ocorrem fatores externos com ameaças a um ente, uma das opções para minimizar ou neutralizar a ameaça é estabelecer ações factíveis, por se tratar de fator externo e que não permite governabilidade.

Os tributos como IPTU, ISSQN, IRRF, ITBI representam 89,6\% da receita tributária, no entanto quando o referencial é a receita corrente, esse percentual representa 12,6\%. Dentre os principais impostos, no período citado, o IPTU apresentou um crescimento médio de 17\% com variação no período 2007 a 2013 de 102\%; o ISSQN 
crescimento médio de $15 \%$ e variação no período de $91 \%$, o IRRF crescimento médio de $2 \%$ e variação no período de $14 \%$; o ITBI com média de crescimento de $25 \%$ e variação de $149 \%$ no período.

As transferências correntes têm uma representatividade média anual de 77,57\%, mesmo que este tipo de receita, conforme art. $12 \S 2^{\circ}$ da Lei 4320, não exija contraprestação direta ou indireta de serviços. O alto nível de dependência que o município tem do Estado e da União acaba influenciando no desenvolvimento local, uma vez que fica suscetível a oscilação de receita do ente estadual e federal e ainda parte dessa transferência vem atrelada às determinações legais como o caso de saúde, educação etc.

Quando comparadas as transferências correntes e receita bruta no período de 2007 a 2013, o percentual médio anual é de 68\%; no entanto, ocorre uma oscilação de 2007/2008. Para 2009 ocorre uma queda de 13 pontos percentuais, voltando a crescer 9 pontos percentuais de 2009/2010, com uma queda de 2011/2012, de 8 pontos percentuais, e, em 2013 um acréscimo de 9 pontos. Porém este processo necessita de direcionamento claro para dar continuidade aos projetos de longo prazo e ampliar o percentual de queda das transferências.

\subsection{Análise Qualitativa}

A análise SWOT situa o planejador diante do cenário encontrado, e, no caso específico, foram identificadas 24 (vinte quatro) fraquezas, 29 (vinte nove) forças, 8 (oito) ameaças e 43 (quarenta e três) oportunidades. O que retrata uma situação confortável pela predominância de forças e oportunidades, refletindo os dados de PIB, PIB percápita, da diversidade de produção agrícola, pecuária, da instalação de indústrias e empresas, das oportunidades de localização e por ser portal do Xingu. Posteriormente correlacionou-se o resultado do ambiente interno e externo da organização, que revelou uma postura estratégica clara em relação à organização em estudo. 


\section{Quadro 1 - Correlação entre análise interna e externa}

\begin{tabular}{|c|c|c|c|c|}
\hline & & & \multicolumn{2}{|c|}{ Análise Interna } \\
\hline & & & \multicolumn{2}{|c|}{ Predominância de } \\
\hline & & & Pontos Fracos & Pontos Fortes \\
\hline \multirow{2}{*}{ 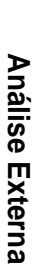 } & \multirow{2}{*}{ 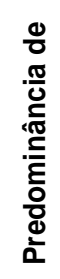 } & Ameaças & $\begin{array}{c}\text { Postura } \\
\text { Sobrevivência } \\
(\mathbf{8 ; 2 4 )}\end{array}$ & $\begin{array}{c}\text { Postura } \\
\text { Manutenção } \\
(8 ; 29)\end{array}$ \\
\hline & & Oportunidade & $\begin{array}{c}\text { Postura } \\
\text { Crescimento } \\
(43 ; 24)\end{array}$ & $\begin{array}{c}\text { Postura } \\
\text { Desenvolvimento } \\
(43 ; 29)\end{array}$ \\
\hline & & & $\begin{array}{l}\text { inovação; } \\
\text { internacionalização; } \\
\text { joint venture; } \\
\text { expansão. }\end{array}$ & $\begin{array}{l}\text { de mercado; } \\
\text { de produtos; } \\
\text { financeiro; } \\
\text { de capacidade; } \\
\text { de estabilidade; } \\
\text { de diversificacąâ; } \\
\text { - horizontal; } \\
\text { - concêntrica; } \\
\text { - conglomerada; } \\
\text { - interna; } \\
\text { - mista. }\end{array}$ \\
\hline
\end{tabular}

Fonte: Adaptado de OLIVEIRA (2002)

A postura estratégica de desenvolvimento expõe uma predominância de oportunidades com pontos fortes, isto significa que, além de a organização estar preparada, existe um mercado para atuação. Como registrado anteriormente é uma situação confortável e um caminho a trilhar diante da composição de cenário.

A postura estratégica indicada pela correlação de ambientes é de desenvolvimento, mas por uma questão de cautela e bom senso, a sugestão é que se adote uma postura mista, visto que a diferença entre pontos fracos e fortes é de apenas 17,25\%. Dessa forma, a estratégia apropriada é de crescimento e desenvolvimento que abarcam uma quantidade maior de alternativas que contempla um número maior de empresas e amplia o lastro para geração de receita própria. 


\section{PROPOSIÇÃO DA IDENTIDADE INSTITUCIONAL E OBJETIVOS ESTRATÉGICOS}

\subsection{IDENTIDADE INSTITUCIONAL}

Negócio: Conduzir efetivamente a aplicação dos recursos públicos e a gestão das políticas públicas.

Missão: Promover integração local, regional, nacional e internacional com foco em sustentabilidade assegurando o crescimento e o desenvolvimento da região.

Visão de futuro: Manter-se como portal do Xingu honrando a exuberância da natureza, utilizando os recursos disponíveis com responsabilidade, para que as gerações futuras encontrem motivos de se orgulhar dos pioneiros e seus descendentes, além de ter acesso à natureza com seus rios, fauna, flora etc.

Valores: Compromisso: Atuação conjunta dos atores sociais: órgãos, cidadão e da sociedade em prol do município com fim de transformar a realidade;

Participação: Empoderamento dos cidadãos nas decisões e no destino do município, com emancipação individual e consciência sistêmica para suplantar a dependência social e dominação política;

Transparência: Gerir as políticas e o orçamento público lastreado pelos princípios da legalidade, impessoalidade, moralidade, publicidade e eficiência;

União: Manter a linha mestra motivadora, desde o surgimento do projeto, a preservação das raízes culturais, valores, persistência e a busca de alternativas com respeito à vida e à natureza;

Respeito: Respeitar as diversidades culturais, sociais, étnicas, ambientais e a experiência produtiva dos pioneiros e tratar com equidade o cidadão.

\subsection{PROPOSIÇÃO DOS OBJETIVOS ESTRATÉGICOS}

\section{OBJETIVO ESTRATÉGICO 1:}

Desenvolver um programa prioritário de preservação permanente de APPS e com ações secundárias: definir claramente a preservação e a manutenção das nascentes por lei municipal, ampliar o recolhimento de embalagens de agrotóxicos estendendo aos municípios circunvizinhos porque é impossível limitar a contaminação do lençol freático.

\section{OBJETIVO ESTRATÉGICO2:}

Promover a formação do ser humano por meio da educação, desenvolvendo um projeto único para as escolas estaduais e municipais coordenado pela secretaria de educação, o sistema "S" envolvendo todos os atores sociais com papéis definidos e compromissos assumidos. 


\section{OBJETIVO ESTRATÉGICO 3:}

Criar um programa de infraestrutura com projetos: energético, comunicação; saneamento básico; saúde para atuação preventiva e corretiva; anel viário para desviar a circulação de veículos pesados do centro; distrito industrial e aterro sanitário;

\section{OBJETIVO ESTRATÉGICO 4:}

Desenvolver um programa preventivo para saúde da família com a conscientização para os focos de hanseníase, tuberculose, dengue, infecção respiratória aguda, usando dos meios de comunicação, atores sociais e, ainda, estruturar um centro saúde de atendimento de alta complexidade;

\section{OBJETIVO ESTRATÉGICO 5:}

Criar uma incubadora de conhecimento técnico básico de administração/economia, para dar suporte aos empreendedores, com foco na agricultura familiar, na agroindústria, no artesanato e aproveitar os programas disponibilizados pelo governo federal, envolvendo todos os atores sociais, seja no recebimento ou na disponibilização da informação, inclusive com abertura de pequenas empresas ou mesmo cooperativas.

\section{OBJETIVO ESTRATÉGICO 6:}

Ampliar e fortalecer a atuação da ADECAN legitimando as discussões dos recortes integrativos que permeiam as particularidades do município, dando vez e voz à sociedade, aos cidadãos, aos pioneiros que adquiriram conhecimento com as intemperes vivenciadas. Entende-se como recorte integrativo grupos de cidadãos que defendem causas específicas e que somam para o conjunto de potencialidades existentes no município. Com isso ampliase o poder de governança, bem como neutraliza os pontos fracos e minimiza as ameaças.

\section{OBJETIVO ESTRATÉGICO 7:}

Elaborar projeto de melhoria continua dos processos internos, por meio da gestão de processo.

\section{Considerações Finais}

Esta pesquisa atingiu o objetivo de realizar o diagnóstico e propor objetivos estratégicos de longo prazo ao município, bem como os objetivos específicos de realizar diagnóstico sobre forças, fraquezas, ameaças e oportunidades para executar análise SWOT; utilizar a matriz GUT para identificar e priorizar as principais sugestões e a identidade institucional. Assim como, ratifica as hipóteses da falta de cultura de planejamento, recursos humanos de modo geral com pouca qualificação, mas a hipótese de resistência à elaboração de planejamento foi refutada, já que da gestão atual estiveram presentes todos os 
secretários e ficaram responsáveis por conduzir o levantamento das sugestões com ampliação aos setores envolvidos e áreas afins. Os segmentos da sociedade e organizações também contribuíram sistematicamente em todos os fóruns, com destaque para a Associação de Desenvolvimento de Canarana - ADECAN que foi a principal articuladora de todas as etapas de realização dos fóruns.

As potencialidades locais serviram de base ao crescimento e ao desenvolvimento da região, podendo ser destacados a agricultura, pecuária, rotatividade de cultura agrícola, consórcio entre agricultura e pecuária, localização, preservação das nascentes, a busca de conhecimento e a união dos atores sociais entre outras. Entretanto, algumas questões centrais discutidas nos fóruns não tiveram a relevância necessária como a questão da sustentabilidade. A sustentabilidade, que neste caso é tratada como um conjunto de fatores econômicos, sociais, ambientais, está na secretaria da agricultura e meio ambiente com ações pontuais de pequeno porte e não tem base sólida para se estruturar a longo prazo, vez que o município tem quarenta e dois anos e passou por vários ciclos da terra virgem a produção, da produção ao exaurimento e ao desmatamento desmedido da terra, do exaurimento e desmatamento a recomposição paulatina do solo pelo aprendizado adequado, pelas informações adquiridas e pela conscientização. Motivo pelo qual recebeu a proposição de um objetivo estratégico

Entretanto a questão socioambiental recebe a mais de uma década por meio de organizações não governamentais como ISA, entre outras ações coordenadas desenvolvidas com agricultores familiares, etnias indígenas como Kisêdjê, Ikpeng, Kaiabi, Yudja pequenos, médios e grandes empresário-produtores, professores, técnicos, gestores, estudantes que recebem orientações e a formação de agentes sociais. Essas ações foram norteadas pela campanha Y Ikatu Xingu, Projeto Governança, Festival de Sementes de Canarana, casa de sementes e a técnica apelidada de "muvuca", que trouxe menos trabalho, eficiência econômica e ecológica, 2400 ha de área florestal em processo de restauração, criação de rede de sementes, nativas do Xingu, geração de renda para 300 famílias indígenas e agricultores familiares e venda de 75 toneladas de sementes até 2010 com renda de R\$ 700 mil. 
A constatação desses dados leva-nos a perceber que o município de Canarana não pode ser comparado com demais municípios localizados no mesmo paralelo e teoricamente com as mesmas condições para o agronegócio, por diversos motivos: 1) por se trata de uma região onde a grande maioria dos produtores tem em torno de 500 há que são considerados pequenos; 2) a importância socioambiental extrapola os limites do município, que contribui para formação da bacia do Xingu e Amazônica; 3) tem conhecimento acumulado pelas intemperes vivenciadas pelos pioneiros e seus descendentes; 4) têm a união e a preservação/ tradição de trabalho e cultura; 5) tem um trabalho ambiental embrionário que merece respeito pela capacidade de envolvimento de atores; 6) têm culturas e resgates de conhecimento com a contribuição dos anciãos das etnias que estão auxiliando na recuperação dos tipos de sementes e como são conhecidas na língua de cada etnia; dos períodos de floradas e dos polinizadores; 7) pela integração entre índios e pioneiros e pelo entendimento único da importância do Xingu, seja rio, bacia ou território. A capacidade dessa junção talvez seja o maior ganho para os habitantes da região Centro Oeste e Norte.

Sobre a infraestrutura, que também abarca um conjunto de conhecimento diverso e complexo, é necessária a elaboração de projetos para suprir o município com energia, sinais de comunicação, estrutura viária já que estes fatores são indispensáveis ao crescimento e instalação de indústria. A infraestrutura ligada às questões de saneamento básico vão impactar direta ou indiretamente os setores de saúde, educação, serviço, comércio, turismo ecológico e também o meio ambiente. Não se de propôs um objetivo estratégico para turismo porque nesse momento a infraestrutura ainda é precária para um fluxo maior de turistas.

A diferença entre pontos fracos e fortes é de apenas 17,25\%, dessa forma a estratégia apropriada é de crescimento e desenvolvimento que abarcam uma quantidade maior de alternativas, contempla um número maior de empresas e amplia o lastro para geração de receita própria. Além da peculiaridade socioambiental da região que abrirá caminhos até então pouco percorridos e com a oportunidade de se fazer história e tornar-se modelo de estudo para os demais municípios brasileiros.

Este trabalho não teve a pretensão de exaurir o assunto, porque para propor objetivos estratégicos de longo prazo a um município deve-se ter uma equipe 
multidisciplinar pela amplitude, pela diversidade de dados para pesquisa. Propôs-se sete objetivos estratégicos prioritários para desenvolver a cultura de pensar em longo prazo que é adquirido no decorrer da execução e requer disciplina pela equipe de gestores. A região leste mato-grossense é um campo fértil para realização de estudos relevantes para humanidade, pois é uma região explorada sistematicamente a partir da década 70, portanto jovem e que depois de 40 anos obteve a consciência dos tesouros naturais que guarda, mas que tudo se encontra incipiente e com a necessidade de pesquisadores com conhecimento e visão sistêmica para contribuir assertivamente para as melhores ações, levando a região a atingir a qualidade de vida com um crescimento, desenvolvimento e com inovação socioambiental.

\section{Referências}

ACKOFF, Russell L. Planejamento Organizacional; Tradução de Marco Túlio de Freitas. Rio de Janeiro: Livros Técnicos e Científicos, 1979.

ACKOFF, Russell L. Redesig ning the future: a systems approach tosocietal problems. New York: John Wiley, 1974.

ALVES, Heber Queiros, REZENDE, Ana Carolina Pinto, SPOSITO Rafael de Carvalho. Geoprocessamento como Ferramenta de Conservação de Recursos Hídricos e de Biodiversidade: Um Estudo de Caso para o Município de Canarana - MT. Anais XIV Simpósio Brasileiro de Sensoriamento Remoto, Natal, Brasil: INPE, 25-30, 2009.

ANSOFF, Igor. Corporate strategy. New York: McGraw Hill, 1965

AURELIANO, Liana M. "Descentralização de políticas sociais: alguns exemplos da saúde, educação e assistência", in Debates: Poder local face às eleições de 1996 (n. 10). São Paulo: Konrad-Adenauer-Stiftung, p.25 a 31.

DRUCKER, Peter, F. Prática de administração de Empresa. Rio de Janeiro: Fundo de cultura. 1962.

FAYOL. J. H. Administração Industrial e Geral. São Paulo: Atlas, 1950.

IBGE - INSTITUTO BRASILEIRO DE GEOGRAFIA E ESTATISTICA. Disponível em:<www.ibge.gov.br>. Acesso em: 12 de fevereiro, 2010.

IBGE - INSTITUTO BRASILEIRO DE GEOGRAFIA E ESTATISTICA. Disponível em:<www.ibge.gov.br>. Acesso em: 19 de junho, 2011.

ISA. Município de Canarana. Y Ikatu Xingu - Salve a Água Boa do Xingu. Apresentação de Canarana de Campo, 2012. 
KAPLAN, Robert S; NORTON, David P. A Estratégia em Ação: Balanced Scorecard. $4^{\text {a }}$ ed. Rio de Janeiro: Campus, 1997.

KEPNER, Charles H.; TREGOE, Benjamin B. O administrador racional. São Paulo: Atlas, 1981.

KOTLER, Philip. Administração de Marketing: a edição do novo milênio. São Paulo: Prentic Hall, 2000.

LORANGE, P. Formal Planning Systems: Their Role in strategy formulation and implementation. In: D. E. Schendel and C. W. Hofer. eds., Strategy Management: A de New View of business policy and planning (Boston: Little, Brown, 1979)

TCE-MT. Tribunal de Contas do Estado de Mato Grosso - Julgamento sobre Contas Anuais prestadas pelo prefeito de Canarana do Estado de Mato Grosso 2008. Cuiabá: TCE, 2008.

TCE-MT. Tribunal de Contas do Estado de Mato Grosso - Parecer Prévio sobre Contas Anuais prestadas pelo governador do Estado de Mato Grosso 2008. Cuiabá: TCE, 2009

TCE-MT. Tribunal de Contas do Estado de Mato Grosso. Espaço do cidadão. Cuiabá: TCE, 2009 - 2014. Disponível em: www.tce.mt.gov.br, Acesso em: 15/04/2014

MATUS, Carlos. La Planificación de Situaciones. México: Fondo de Cultura Econômica. 1980.

MATUS, Carlos. O Plano como aposta. O plano e a governabilidade do homem sobre as situações. Organizadores James Giacomoni e José Luiz Pagnussat. Brasília: ENAP. 2006 v.2.

MATUS, Carlos. Política, Planejamento \& Governo. Brasília: IPEA,1993.

MATUS, Carlos. Política, Planejamento \& Governo. 2ª ed. Brasília: IPEA,1996. V.2

MINTZBERG, Henry. Et. all. Safári das Estratégias. Porto Alegre: Bookman, 2000.

OLIVEIRA, Djalma de Pinho Rebouças de. Planejamento Estratégico: conceitos e metodologia. $18^{a}$ ed. São Paulo: Atlas, 2002.

PFEIFFER, Peter Planejamento estratégico municipal no Brasil: uma nova abordagem. Brasília: ENAP, 2000.

PORTER, Michael. Estratégia competitiva: técnicas para análise de indústrias e da concorrência. $7^{\text {a }}$ ed. Rio de Janeiro: Campos, 1986

PNUD, 2000. Disponível em: http://www.pnud.org.br/HDR/Relatorios-DesenvolvimentoHumano-Globais. Acesso em 10 de fevereiro de 2014.

Prefeitura Municipal de Canarana. Dados referentes ao município. Apresentação em Power point pela Secretaria Municipal de Agricultura e Meio Ambiente, 2013 
RASMUSSEN, U.W. Manual da metodologia do planejamento estratégico: ferramenta científica da transição organizacional do presente para o futuro adotado para o âmbito operacional brasileiro. São Paulo: Aduaneira, 1990.

RIBEIRO, Alexandro Rodrigues. A colonização promovida por empresas e famílias do Centro-Sul do Brasil na Amazônia Mato-Grossense. Belém/PA. 2013. 259 f (Tese de Doutorado em Desenvolvimento Sustentável) - Programa de Pós-Graduação em Desenvolvimento Sustentável do Trópico Úmido, Universidade Federal do Pará, Núcleo de Altos Estudos Amazônicos, Belém, 2013.

STEINER, G.A., Top Management Planning, Mamillan, Nova Iorque, 1969.

TAYLOR, Frederick. W. The Principle sof Scientific Management, New York: Harper \& Bros, 1911.

TONINI, Nelsi Salete. O planejamento e saúde mental no contexto da refori psiquiátrica: um estudo dos municípios da região oeste do Paraná. Ribeirão Preto: USP, 2005.

VILLAS BOAS, André (Org.) Y IKATU XINGU. Uma campanha de responsabilidade socioambiental compartilhada em defesa das nascentes do Xingu. Setembro de 2008.

VILlAS BOAS, André. (Org.) Dê olho na bacia do Xingu. São Paulo: Instituto Socioambiental, 2012. (Série Cartô Brasil Socioambiental; v.5).

Submetido em: 07/03/16

Aceito em: 21/06/16 